\title{
La niñez encarcelada: Lineamientos en cuanto a una posible reforma al Régimen Penal Juvenil. La baja de edad de inimputabilidad detrás de una supuesta reforma progresista
}

The imprisoned childhood. Guidelines for a Juvenile Criminal Regime potential reformation. The reduction of the legal age of criminal responsibility behind a so-called progressist reformation

Crianças encarceradas: Diretrizes sobre uma possível reforma do Regime Criminal Juvenil. A baixa idade de intolerância por trás de uma suposta reforma progressiva

L'enfance emprisonnée. Des lignes directrices concernant une éventuelle réforme du régime pénal des mineurs. Le bas de l'âge d'imputabilité derrière une prétendue réforme progressive

\begin{tabular}{l|l} 
Stefanía Giovanna Alba Nájera & \\
& $\begin{array}{l}\text { Universidad Nacional } \\
\text { de La Plata }\end{array}$
\end{tabular}

Revista Derechos en Acción / ISSN 2525-1678 / e-ISSN 2525-1686 Año 4/NNo 10 Verano 2018/2019 (21 diciembre a 21 marzo), 309-325 DOl: https://doi.org/10.24215/25251678e255 ORCID: https://orcid.org/0000-0003-0868-9327 Recibido: 19/12/2018 Aprobado: 01/03/2019

Resumen: El trabajo analiza una iniciativa del gobierno argentino para reformar la edad de imputabilidad de los delitos. Este proyecto no viene solo. En realidad la llamada "baja" forma parte de algo más ambicioso:

\footnotetext{
1 Abogada, Facultad de Ciencias Jurídicas y Sociales, UNLP, realizando la Maestría en comunicación y criminología mediática en Facultad de Periodismo y Comunicación Social, UNLP. Pasante en el Foro para la Justicia Democrática -Fojude-.
} 
reformar y adecuar el Régimen Penal Juvenil a acorde a los parámetros internacionales; deuda un tanto postergada de la democracia. Creemos visualizar una veta positiva en el proyecto en tanto adecúa, o intenta hacerlo, el viejo régimen de responsabilidad juvenil con los parámetros internacionales, pero cuidado; esconde ciertos rasgos punitivitas alentados probablemente por ciertos sectores sociales, junto con las agencias mediáticas, sumado a la ola de reformas de corte "mano dura", en un contexto social neoliberal que no brinda las reales oportunidades que requieren los jóvenes como ser vivienda, educación, salud, desarrollo personal, entre un cumulo de derechos de escaso desarrollo por estos días

Palabras claves: imputabilidad. Adolescentes. Régimen Penal Juvenil

Abstract: This work analyses an Argentinian government's initiative for reformation of the. This Project does not come alone. Actually, the so-called "reduction" is part of something more ambitious: to reform and to adapt the Juvenile Criminal Regime according to international parameters; but beware; it hides certain punitive features, probably encouraged by some social sectors, as well as the media agencies, in addition of the tendency of "firm hand", in a neoliberal social context that does not provide the real opportunities that Young people require, such as a dwelling, education, wealth, personal development, among others, of scanty development in the present days.

Keywords: legal age of criminal responsibility, teenagers, Juvenile Criminal Regime

Resumo: 0 artigo analisa uma iniciativa do governo argentino para reformar a idade de imputabilidade dos crimes. Este projeto não vem sozinho. Na realidade, a chamada "baixa" faz parte de algo mais ambicioso: reformar e adaptar o Regime Penal Juvenil de acordo com parâmetros internacionais; dívida um pouco adiada da democracia. Acreditamos que visualizamos uma veia positiva no projeto, se encaixa, ou tenta fazê-lo, o antigo regime de responsabilidade juvenil com os parâmetros internacionais, mas tenha cuidado; esconde certas provavelmente punitivitasalentados por certos setores sociais, juntamente com as características agenciasmediáticas, combinados com a onda de reformas corte "duro" em um contextosocial neoliberal que não oferece oportunidades reais que exigem jóvenescomo ser habitação, educação, 
saúde, desenvolvimento equipe, entre um conjunto de direitos pouco desenvolvidos nos dias de hoje.

Palavras-chave: imputabilidade. Adolescentes Regime Criminal Juvenil

Résumé: Ce travail analyse une initiative du gouvernement argentin pour à réformer l'âge d'imputabilité des crimes. Ce projet ne vient pas seul. Vraiment, la "basse» fait partie d'un projet plus ambitieux: réformer et adapter le régime pénal des mineurs selon les paramètres internationaux; une vieille dette de la démocratie. Nous percevions une veine positive dans le projet, car il s'adapte, ou tente de le faire, à l'ancien régime de responsabilité des mineurs selon paramètres internationaux, mais soyez prudent; il cache certaines caractéristiques punitives encouragées par certains secteurs sociaux, ainsi que les agences de médias, ajoutées à la vague de réformes de "main de fer" dans un contexte social néolibéral qui n'offre pas des opportunités réelles aux jeunes, telles que le logement, l'éducation, santé, développement personnel, parmi d'autres droits peu développés actuellement.

Mot-clés: Imputabilité. Les adolescents. Régime criminel juvénile.

\section{Presentación}

No es la primera vez, ni lastimosamente será la última, en que las políticas criminales de nuestro Estado busquen inflacionar punitivamente nuestra sociedad. Tampoco es la primera, ni será la última vez, que sean los jóvenes las víctimas de este bumerán de discusiones políticas, jurídicas y mediáticas con el único fin de hacerle creer a cierto sector de la sociedad, reclamante generalmente de endurecimiento de penas, que la toma de dichas medidas son la solución mágica a todos los problemas sociales existentes. En definitiva se trata de maniobras distractoras para que el foco del problema se puntualicé en los pibes y las pibas, ocultando los problemas en materia de desarrollo social y económico que sufre nuestro territorio.

Concretamente ahora, justamente cuando también se propone enviar un proyecto de nuevo código penal de la Nación, 
incluyente por ejemplo de la doctrina Chocobar entre otras cosas, el gobierno pretende reformar la edad de imputabilidad de los delitos en la Argentina. Esto no es novedad, ya que desde hace algunos años se discute la baja de edad de imputabilidad.

Este proyecto no viene solo. En realidad la llamada "baja" forma parte de algo más ambicioso: reformar y adecuar el Régimen Penal Juvenil a acorde a los parámetros internacionales; deuda un tanto postergada de la democracia. Podríamos decir entonces que detrás de una supuesta reforma progresista en el marco del programa de Justicia $2020^{2}$, se esconde un ítem, un punto, de total controversia anclado en la idea de estigmatizar aun más a los jóvenes y desconocer que en definitiva es una forma de exclusión y no de inclusión social. Una manera más de encarcelar, de institucionalizar personas, cada vez a más corta edad, produciendo entonces de esa manera mayores condiciones de regresividad para quienes sufren la imposición de la pena. Un modelo de mayor castigo, ampliando de esta manera el Estado de policía.

\section{Desarrollo}

Según un relevamiento realizado por UNICEF, hay actualmente alrededor de 1305 jóvenes privados de la libertad en centros cerrados. Casi la totalidad son varones, argentinos, mayoritariamente comprendidos entre los 16 y 17 años de edad. ${ }^{3}$

Es importante de antemano advertir que estamos hablando de un tema por demás sensible; se trata de aplicar sanciones ni más ni menos que a personas que son consideradas niños/as. De por si toda temática referida al encarcelamiento de personas requiere de una sensibilidad y empatía por parte de la comunidad en su conjunto.

2 Este programa se presenta como "una justicia cercana a la comunidad, moderna, transparente e independiente".

3 "Las voces de las y los adolescentes privados de la libertad en Argentina", UNICEF, CENEP, Noviembre 2018. https://www.unicef.org/argentina/informes/las-voces-de-los-ylas-adolescentes-privados-de-libertad 
Según la Convención de Derechos del Niño, a la cual nos ceñiremos como pilar en todo este trabajo, en su artículo primero establece que toda persona que no haya alcanzado la edad de 18 años es considerado niño/a, a salvo de que una legislación determine una edad anterior para la obtención de la mayoría de edad. En nuestro país, en el año 2009 precisamente, con la ley $\mathrm{N}^{\mathrm{0}} 26.579$, fue cuando se bajó la edad para considerarse mayor de edad. Se pasó de 21 años a 18 años, quedando igualada entonces al estándar internacional.

Entendemos de todos modos que pese a que nos resulte por demás rechazable una posible reforma a la edad de punibilidad de delitos, hay una discusión como dijimos quizás aun mayor por detrás de todo este debate mediático/judicial y tiene que ver con el llamado Régimen Penal Juvenil. Es inminente la necesidad de su reforma y su adecuación a estándares internacionales en suma sintonía con el respeto por los Derechos Humanos de niños, niñas y adolescentes. La incertidumbre generada es quizás el no saber si están dadas las condiciones favorables para una reforma de tal envergadura considerando que estamos frente a un gobierno que podríamos dar a llamar de "mano dura", de "tolerancia 0", donde ya hemos asistido a reformas más severas en cuanto a los castigos como por ejemplo la reformada ley 26660 de Ejecución Penal Nacional.

Históricamente en Argentina, específicamente durante la última dictadura militar, se ha bajado la edad a 14 años y en el mismo período se ha sancionado el Régimen Penal Juvenil (ley 22. 278, 1980). Luego con el regreso de la democracia la edad de inimputabilidad se estableció entonces en los 16 años. Pero pese el aumento en la edad establecida en la ley, el Régimen Penal Juvenil no ha sido adecuado a los estándares internacionales de derechos humanos. Vale aclarar que, recién diez años después de la sanción del Régimen, nuestro país ratificó mediante ley 23.849 la Convención Sobre los Derechos del Niño (CDN), la que reemplaza la doctrina de la situación irregular por el de la protección integral de derechos. 
Algunos puntos destacables en torno a la consideración de la niñez por la Convención han sido:

- La existencia de políticas básicas universales para todos los niños y niñas.

- El niño y la niña dejan de ser objeto de derechos para pasar a ser sujetos de los mismos; y el respeto de dichos derechos debe estar garantizado por el Estado.

- Se reduce la incidencia del juez en los procesos; el mismo solo interviene cuando se trata de problemas jurídicos o conflictos con la ley penal, y no cuando considera que hay "peligro material o moral", lo cual constituye un concepto de por si indefinible, dándole un marco amplísimo en la toma de decisiones tanto materialmente como en la duración de las medidas a adoptar.

- Se rompe con el sistema de patronato por parte del Estado, quien deja de ser "patrón" para convertirse en promotor del bienestar de niños y niñas.

- Se prioriza siempre la relación del niño/a con su familia; intentando impedir por todos los medios posibles la separación del joven de su familia.

- Se establece la obligación de oír al niño/a; quien además cuenta con la obligatoriedad de una defensa oficial y un impedimento ante cualquier tipo de privación de la libertad.

- Se cambia el foco de la responsabilidad frente a los niños/as; ya no se trata de áreas meramente judiciales y/o administrativas consideradas "de menores" sino que se requieren de toda una serie de políticas públicas provenientes de organismos Estatales descentralizados.

Existen otros instrumentos internacionales sumamente importantes para lograr una formidable coexistencia con el antiguo Régimen nacional. Por un lado las "Reglas mínimas de las Naciones Unidas para la administración de justicia de menores" o mayormente conocidas como Reglas de Beijin, las Directrices de las Naciones Unidas para la prevención de la delincuencia 
juvenil, conocidas como Directrices de Riad y las Reglas mínimas de las Naciones Unidas sobre las medidas no privativas de la libertad, también llamadas Reglas de Tokio.

Es importante tener en cuenta también la Observación General No 10 del año 2007, emitida por el Comité de los Derechos del Niño ${ }^{4}$; órgano de expertos independientes que supervisa la aplicación de la CDN por sus Estados Partes. En el mismo se alienta a los Estados parte a elaborar y aplicar una política general de justicia de menores a fin de prevenir y luchar contra la delincuencia juvenil. Pone de relieve la importancia de promover el desarrollo pleno y armonioso de la personalidad, las aptitudes y la capacidad mental y física del niño. Respecto de la edad de punibilidad el Comité recomienda elevar las edades por ejemplo de los estados que la establecen en 12 años, considerando aconsejable su aumento a por lo menos 16 años, acompañando de esa manera la madurez emocional, mental e intelectual. Establece que toda persona menor de 18 años en el momento de la presunta comisión de un delito debe recibir un trato conforme a las normas de la justicia de menores.

Las normativas internacionales entonces no establecen un límite de edad para la responsabilidad penal juvenil pero el Comité por ejemplo recomienda que se aplique un solo sistema de responsabilidad penal juvenil; es decir, que el Régimen sea aplicado igualitariamente a los infractores menores de 18 años, en consonancia por supuesto con lo dispuesto por la CDN y demás instrumentos. Luego el informe toma un rumbo más procesalista, nos habla de las garantías de un juicio imparcial; donde establece condiciones respecto a los órganos intervinientes en el proceso, el tiempo de duración y los derechos y garantías que le corresponden al supuesto infractor. Resalta por último la necesidad de utilizar medidas alternativas a la prisión; estableciendo a la privación de la libertad como último recurso y por el tiempo más breve posible.

4 https://www2.ohchr.org/english/bodies/crc/docs/crc.c.gc.10_sp.pdf 
La necesidad de adecuar el Régimen Penal Juvenil a los estándares internacionales no ha sido sólo una cuestión doctrinaria. Jurisprudencialmente inclusive la Corte Internacional de Derechos Humanos, en el caso "César Alberto Mendoza y otros vs. Argentina" de fecha 14 de mayo de 2013 ha establecido en su recomendación cuarta al Estado Argentino, que disponga de las medidas legislativas y de otra índole para que el sistema de justicia penal aplicable a adolescentes por conductas cometidas siendo menores de 18 años, sea compatible con las obligaciones internacionalmente dispuestas en materia de protección y promoción de niños y niñas. En el caso concreto la Corte encontró responsable a la Argentina por violación a los estándares internacionales en justicia penal juvenil ante la imposición de penas perpetuas a menores de edad, en igualdad de condiciones que a un mayor de edad.

UNICEF por su parte ha lanzado un documento llamado "Ideas para contribuir al debate sobre la Ley de Justicia Penal Juvenil" ". En el mismo resalta lo que venimos desarrollando; la necesidad de que Argentina se adecue a la normativa internacional. Nos habla de reinserción social en vez de represión; ofreciendo a los adolescentes oportunidades educativas, de formación laboral y recreativas, para de esta manera alejarlos del delito. Destaca la necesidad de aportar fondos económicos para el mejor desarrollo de esta justicia penal juvenil y el nombramiento de jueces, fiscales, defensores y equipos técnicos interdisciplinarios especializados en la materia de niñez y adolescencia. Un punto importantísimo de la observación de UNICEF es la aclaración clara y precisa de la innecesaridad de la baja de edad de inimputabilidad para la realización de la reforma legislativa del Régimen Penal Juvenil, interpretando dicha acción en todo caso como un retroceso en materia de derechos humanos y como una medida regresiva. En cuanto a los medios de comunicación confiesa que pese a que los mismos

\footnotetext{
5 https://www.unicef.org/argentina/sites/unicef.org.argentina/files/2019-01/6_ Posicionamiento-Justicia-Penal-Juvenil_0.pdf
} 
relacionen la idea de seguridad con la edad de los infractores de las normas, evidencia que no existen datos precisos que aseveren la relación inseguridad/delincuencia juvenil. Evidencia que los datos existentes relacionan los delitos cometidos por jóvenes son generalmente delitos contra la propiedad. Por último deja en claro que la privación de la libertad tiene que ser la última medida a adoptar y por el menor tiempo posible. En definitiva el documento propone medidas alternativas de reparación de conflictos.

Es interesante recordar que a nivel interno nuestro país cuenta con una Ley de Protección Integral de los Derechos de las Niñas, Niños y Adolescentes ${ }^{6}$, la cual no podría ser dejada de lado frente a la adecuación pretendida en el Régimen Penal Juvenil. Aquella ley introduce conceptos fundamentales como el del Interés Superior del Niño, la asignación de responsabilidad estatal, comunitaria y familiar. En cuanto nos habla de la libertad personal dirige las disposiciones a adoptar a la normativa vigente, lo que sería la derivación a la ley 22.278. Es de suma importancia el artículo 27 el cual se cataloga como "GARANTIAS MINIMAS DE PROCEDIMiento. GARANTIAS EN LOS PROCEDIMientoS JUDICIALES O ADMINISTRATIVOS”. En él se establece el derecho a ser oído, a ser asistido por un letrado preferentemente especializado en niñez y adolescencia, a participar activamente en todo el procedimiento.

Otro punto controversial por lo cual se requiere la reforma del Régimen del que venimos hablando es la unificación nacional del mismo, ya que existen legislaciones locales que tratan de diferentes formas la cuestión. En la Provincia de Buenos Aires por ejemplo existe la ley 13634, la cual regula todo lo referente al "fuero penal del niño".

Podemos destacar que la ley provincial articula de alguna manera a la CDN y a su vez al régimen nacional de protección de niños, niñas y adolescentes desarrollado precedentemente.

6 http://servicios.infoleg.gob.ar/infoleglnternet/anexos/110000-114999/110778/norma.htm 
De todos modos cuando debe expedirse sobre la edad de punibilidad nos remite a la normativa nacional: "Artículo 32. El presente régimen es aplicable a todo niño punible, según la legislación nacional, imputado de delito en jurisdicción territorial de la provincia."

El último y reciente proyecto de reforma de Régimen Penal Juvenil, en el ámbito del PROGRAMA JUSTICIA 2020 propiciado por el Ministerio de Justicia y Derechos Humanos trae entonces incluida esta reforma en cuanto a la baja de edad de inimputabilidad, además de otros cambios que desarrollaremos a continuación. Se crea entonces un Sistema de Responsabilidad Penal Juvenil que hace que los adolescentes de quince años respondan por determinados delitos. Es dable destacar que ya desde el lenguaje utilizado se elimina por completo la palabra "menor" utilizándose el término "adolescente". Esto no es un capricho gramatical considerando el giro que ha tenido la visión de ese "menor" como un objeto de derecho susceptible de tutela judicial, incapaz, incompleto; pasando a una visión integral otorgándole derechos como por ejemplo el de ser oído y que su opinión sea tenida en cuenta. ${ }^{7}$

Podríamos decir que el proyecto incorpora un doble sistema de responsabilidad penal: por un lado para ciertos delitos para los adolescentes de 15 años, específicamente los reprimidos con pena máxima de 15 años de prisión o más en el Código Penal o en las leyes especiales, y para las personas entre 16 y 18 años se incluirían todos los delitos de acción pública sancionados por el Código Penal o las leyes especiales.

Establece que las edades indicadas anteriormente se entenderán siempre referidas al momento del hecho.

Entre sus principios menciona que la finalidad de este sistema es fomentar en el adolescente el sentido de la responsabilidad

\footnotetext{
7 El derecho del niño/a a ser oído es receptado en el artículo 12 de la CDN y nuestro ya no tan nuevo Código Civil y Comercial ha recogido dicho postulado; ejemplo artículo 27 de dicho código de fondo " "tiene derecho a ser oída en todo proceso judicial que le concierne así como a participar en las decisiones sobre su persona".
} 
por sus actos y procurar su integración social. El proyecto menciona expresamente a la CDN que entendemos debe ser el eje central para esta posible modificación. Integración social es lo que procura, comprendiendo un abordaje integral, interdisciplinario y restaurativo. Hace referencia al interés superior del niño, concepto discutido en la doctrina quizás por considerárselo demasiado abstracto en su definición. La ley de Protección Integral de Niños, Niñas y Adolescentes es quien por primera vez a nivel nacional consagra este derecho, y el mismo proyecto que estamos aquí analizando lo define: se trata de garantizar el disfrute pleno y efectivo de los derechos reconocidos por la CDN y el desarrollo físico, mental, espiritual, moral, psicológico y social del adolescente.

Hace referencia también a una justicia especializada. En este punto considero que en la propuesta la idea resulta muy benéfica pero en la práctica se requieren de diferentes mecanismos, por sobre todo el presupuestario, para consagrar la especialización de dicha justicia.

Establece un plazo máximo para la resolución del procedimiento penal, el cual lo ha establecido en tres años contados desde el acto de la formalización de la Investigación Penal Preparatoria. Un punto controversial quizás en este mismo artículo es la habilitación posible de la aplicación de la prisión preventiva. La misma está establecida como último recurso, no pudiendo exceder de un año, pudiendo el juez renovarla mediante resolución fundada por el mismo lapso de tiempo. La medida se estima deberá ser revisada cada tres meses. Consideramos en este punto como desventajosa totalmente la aplicación de la prisión preventiva, aunque la misma sea enunciada como de un futuro uso excepcional. De por sí la implementación de la prisión preventiva en nuestro país es el caso corriente frente al encarcelamiento masivo de personas. Resultaría extraño, o novedoso, que entonces no se transforme en un recurso de uso frecuente frente a los supuestos jóvenes infractores. Es importante quizás señalar, por más de que no sea objeto de la investigación aquí planteada, que la Comisión 
Interamericana de Derechos Humanos ha presentado en el año 2017 un informe sobre medidas dirigidas a reducir el uso de la prisión preventiva. ${ }^{8}$

El proyecto aclara que la privación de la libertad procederá como último recurso, de forma fundada, revisable, y por el plazo más breve posible.

Al igual que el Régimen vigente, el establecimiento donde se aloje al adolescente deberá ser especializado y contar con PERSONAL CIVIL idóneo para el trato con aquellos. De ningún modo podrán alojarse en centros con personal de las fuerzas de seguridad. Queda prohibido en dichos centros la portación y uso de armas. De más está aclarar que en el presente, indicando sólo el caso de la Provincia de Buenos Aires, las condiciones de detención en general, y en particular la de los jóvenes, dista bastante de lo propuesto en la reforma. ${ }^{9}$

Acorde a los proyectos que han sido tratados respecto a los códigos de procedimientos penales, tanto en Nación como en provincia de Buenos Aires, el proyecto hace mención de "la víctima" dándole participación en el procedimiento que se lleve a cabo con el adolescente, por ejemplo pudiendo celebrar lo que da a llamar como "acuerdos restaurativos" o mismo conciliaciones.

En todo momento se menciona que la tarea con el adolescente debe ser de tipo interdisciplinaria incluyendo asistencia a programas educativos, a programas de formación ciudadana, programas de capacitación laboral, programas deportivos y/o culturales. El equipo interdisciplinario deberá estar formado por al menos tres profesionales de distintas disciplinas, capacitados en justicia restaurativa. La justicia restaurativa es una metodología para solucionar problemas que, de varias maneras, involucra

\footnotetext{
8 "Medidas para reducir la prisión preventiva", Comisión Interamericana de Derechos Humanos, año 2017. http://www.oas.org/es/cidh/informes/pdfs/PrisionPreventiva.pdf

9 Se recomienda la lectura del Informe anual de la Comisión Provincial por la Memoria, " El sistema de la crueldad XII", Agosto 2018. http://www.comisionporlamemoria.org/archivos/ cct/informesanuales/Informe_2018.pdf
} 
a la víctima, al ofensor, a las redes sociales, las instituciones judiciales y la comunidad. Los programas de justicia restaurativa se basan en el principio fundamental de que el comportamiento delictivo no solamente viola la ley, sino también hiere a las víctimas y a la comunidad. Cualquier esfuerzo para solucionar las consecuencias del comportamiento delictivo deberá, en la medida de lo posible, involucrar tanto al ofensor como a las partes ofendidas, y proporcionar la ayuda y el apoyo que la víctima y el delincuente requieren. La justicia restaurativa es un proceso para resolver el problema de la delincuencia enfocándose en la compensación del daño a las víctimas, haciendo a los delincuentes responsables de sus acciones y también, a menudo, involucrando a la comunidad en la resolución del conflicto. La participación de las partes es esencial al proceso y enfatiza la construcción de relaciones y reconciliaciones así como el desarrollo de acuerdos en torno a un resultado deseado por las víctimas y los delincuentes. Los procesos de justicia restaurativa pueden adaptarse a varios contextos culturales y a las necesidades de comunidades diferentes. A través de ellos, el proceso en sí mismo a menudo transforma las relaciones entre la comunidad y el sistema de justicia como un todo. ${ }^{10}$

Otorga la posibilidad de hacer efectivo el cumplimiento de la prisión en el domicilio, sujeto a un monitoreo a través de un dispositivo electrónico. Incluso determina que de ser el caso de una adolescente embarazada directamente se aplicara este modo de cumplimiento de pena. Resulta un tanto extraño en el caso concreto esta disposición ya que asistimos a una realidad de restricción de prisiones domiciliarias en lo que es la justicia de mayores, con lo cual queda un tanto en duda el posible cumplimiento de estas disposiciones.

Establece la prohibición de la aplicación de prisión perpetua y pone un tope de quince años para las sanciones privativas

\footnotetext{
10 "Manual sobre programas de justicia restaurativa", Naciones Unidas, año 2006. https:// www.unodc.org/documents/justice-and-prison-reform/Manual_sobre_programas_de_justicia_restaurativa.pdf
} 
de la libertad en adolescentes. Este punto resulta un tanto importante y trascendental considerando que Argentina es el único país de América Latina con sentencias a reclusión y prisión perpetua a personas menores de edad.

La motivación del presente trabajo es comprender que más allá de la nefasta idea de la baja de edad de imputabilidad existe hoy en día un Régimen de Justicia Penal Juvenil que no satisface en modo alguno los estándares mínimos de protección y promoción de los Derechos Humanos; traducidos en la incorporación de instrumentos internacionales a la normativa vigente a nivel nacional. Es decir, hoy en día, pese a la espera o no tanto en realidad, de una reforma en cuestiones etarias, existen niños y niñas que son víctimas del sistema represivo del Estado. De todos modos pasaremos a mencionar brevemente algunos motivos en particular de porque no debe bajarse la edad de punibilidad, entendiendo que la discusión forma parte además de lo que venimos desarrollando.

- Regresividad: Uno de los puntos, quizás sea el más importante, para ir en contra de la baja de edad de inimputabilidad es la violación al principio de no regresividad y de progresividad: está prohibido regresar a instancias anteriores de la cobertura de un derecho y solo se puede avanzar en dicha cobertura. Haciendo un breve repaso histórico, el Código Penal, sancionado en 1921, establecía la edad de punibilidad en 14 años. Durante el gobierno de Perón, en 1954, se estableció en 16. Luego, durante la última dictadura militar se derogó lo antes establecido volviéndose a la edad de 14 años y creando como ya dijimos el cuestionado Régimen Penal de la Minoridad. En Mayo de 1983, la edad de punibilidad volvió a establecerse en los 16 años. Con esto queremos señalar entonces que pasar a una edad inferior, sean 14 o 15 años, significa un retroceso en los derechos de los niños y niñas.

- La falsa creencia de que solucionará los problemas de inseguridad: En este punto podemos hablar desde diferentes aristas. Por un lado no existe dato alguno que tenga 
relación entre delincuencia juvenil / seguridad / inseguridad. Más bien son los medios de comunicación quienes en la mayoría de las veces alimentan la idea de que los delitos siempre son cometidos por personas menores. Por otro lado, muchas veces estos proyectos de reformas vienen acompañados por algún hecho mediático, por reformas legislativas más amplias (como por ejemplo la discusión también de la reforma del Código Penal ) pero sin advertir que las leyes penales no son retroactivas; es decir que con la baja de edad no se resolverá en todo caso el problema de la supuesta inseguridad.

- La creencia de que en definitiva es un bien para el niño/a, ya que les brinda garantías a los mismos. Esto es absolutamente falso; ha quedado más que claro en este trabajo, o ha sido la idea, comprender que un estado penal no soluciona el conflicto y que por el contrario, se requiere de un Estado inclusivo en políticas sociales, económicas, laborales, educacionales, entre otras.

- La inflación punitiva nunca ha sido solución al conflicto. Ni la propia ley sancionada lo es, menos lo será de la mano de las futuras legislaciones que vienen a dar crecimiento legislativo. Es decir, no es necesario la creación de más leyes. Si en todo caso la aplicación y cumplimiento de lo ya sancionado, especialmente las normativas internacionales no incorporadas al Régimen.

- La falsa idea de que una persona de 15 años comprende la criminalidad de sus actos. El ministro de justicia ha declarado en algunos medios de comunicación que una persona de 15 años comprende perfectamente la criminalidad de sus actos. La contradicción es intentar conciliar la idea de que una persona menor de 18 años es un/a niño/a y en ningún momento puede ser racional exigirle a un/a niño/a la comprensión de la criminalidad de un hecho delictivo. Por el contrario, estamos frente a seres en desarrollo, que lo que menos tienen es una consciencia definitiva de si y una aprehensión de las conductas prohibidas/permitidas. 
Estamos frente a personas adolescentes que palpablemente no cometen sus hechos ilícitos por no motivarse en la norma sino por cuestiones sociales y posiblemente subjetivas también, que los atraviesan

- Porque el Estado en definitiva no tiene control sobre las instituciones de encierro existentes, por ende, será imposible que pueda lograr tenerlo sobre las futuras que pretenda crear.

- Porque como siempre que hablamos del poder punitivo de un Estado no podemos dejar de lado sus principales caracteres. Se trata de un sistema penal discriminatorio, selectivo y estigmatizante. No persigue a todos por igual sino a los más vulnerables, a quienes menos "esfuerzo" tienen que hacer para caer en sus redes. Una vez "atrapados" entonces se les asigna un rol, se los etiqueta. Y esas personas ya no volverán a ser las mismas luego de atravesar un proceso penal, mucho menos si han pasado por algún tipo de institución total. Son por ende los adolescentes el grupo que se encuentra más expuesto a la llamada criminalización secundaria. ${ }^{11}$

- Porque se están produciendo reformas "para la popular", es decir, son reformas que dejarían conformen a un cierto grupo social, encarcelando a los pibes y pibas que en definitiva son víctimas de gobiernos neoliberalistas. Es el mismo Estado quien no les asegura las condiciones de vida que deberían tener y el mismo Estado que intenta castigarlos por en definitiva esas mismas causas.

\section{Conclusiones}

Concluimos de esta manera este intento de mostrar de manera general, los lineamientos de una posible e inminente

\footnotetext{
11 Se entiende al proceso de criminalización secundaria la acción punitiva ejercida sobre personas concretas usualmente realizada por la agencia policial de un Estado.
} 
reforma al régimen penal juvenil. Creemos visualizar una veta positiva en el proyecto en tanto adecúa, o intenta hacerlo, el viejo régimen de responsabilidad juvenil con los parámetros internacionales, pero cuidado; esconde ciertos rasgos punitivitas alentados probablemente por ciertos sectores sociales, junto con las agencias mediáticas, sumado a la ola de reformas de corte "mano dura", en un contexto social neoliberal que no brinda las reales oportunidades que requieren los jóvenes como ser vivienda, educación, salud, desarrollo personal, entre un cumulo de derechos de escaso desarrollo por estos días. 